\section{Medialogy diagram construction on dengue fever}

Viroj Wiwanitkit

Wiwanitkit House, Bangkhae, Bangkok, Thailand; visiting professor, Hainan Medical University, China; adjunct professor, Joseph Ayobabalola University, Nigeria

Correspondence: Professor Viroj Wiwanitkit. Wiwanitkit House, Bangkhae, Bangkok, Thailand Email:wviroj@yahoo.com
Dear Professor Wiwanitkit,

The recent publication entitled "Construction of the discourse on dengue fever in the media" is very interesting ${ }^{1}$. Indeed, dengue is a current public health threat around the world. Problems in diagnosis and treatment can be observed ${ }^{2}$. In addition, the prevention of this disease is usually unsuccessful. In the present report, Ferraz made an interesting observation, stating that "media coverage generally followed the development of dengue fever cases, with more news published during the epidemic periods ${ }^{1}$." Indeed, an important point often ignored is that disease control attempts are an activity usually performed by the medical personnel, although the disease actually affects the general population who are not medical experts. How to communicate and create a positive attitude and behavior in the population at risk is a topic to be discussed. The role of mass communication experts is important for bridging this gap. It has been reported that "there is a close relationship between the number of news stories and the number of reported dengue cases ${ }^{3}$." As a rule, multidisciplinary collaboration is needed to achieve successful dengue and other disease control.

\section{References}

1. Ferraz LM, Gomes IM. Construction of the discourse on dengue fever in the media. Rev Bras Epidemiol. 2012 Mar;15(1):63-74.

2. Wiwanitkit V. Dengue fever: diagnosis and treatment. Expert Rev Anti Infect Ther. 2010 Jul;8(7):841-5.

3. França E, Abreu D, Siqueira M. Dengue epidemics and press coverage. Cad Saude Publica. 2004 Sep-Oct;20(5):1334-41.

Recebido em: 29/03/12 Aprovado em: 14/06/12 